\title{
Accuracy of genomic-polygenic estimated breeding value for milk yield and fat yield in the Thai multibreed dairy population with five single nucleotide polymorphism sets
}

\author{
Bodin Wongpom', Skorn Koonawootrittriron" ${ }^{1, *}$, Mauricio A. Elzo², \\ Thanathip Suwanasopee', and Danai Jattawa ${ }^{1}$
}

\author{
* Corresponding Author: Skorn Koonawootrittriron \\ Tel: +66-2-5791120, Fax: +66-2-5791120, \\ E-mail: agrskk@ku.ac.th \\ ${ }^{1}$ Department of Animal Science, Kasetsart University, \\ Bangkok 10900, Thailand \\ 2 Department of Animal Sciences, University of Florida, \\ Gainesville, FL 32611-0910, USA \\ ORCID \\ Bodin Wongpom \\ https://orcid.org/0000-0003-4559-6197 \\ Skorn Koonawootrittriron \\ https://orcid.org/0000-0001-6170-7876 \\ Mauricio A. Elzo \\ https://orcid.org/0000-0002-9319-3846 \\ Thanathip Suwanasopee \\ https://orcid.org/0000-0002-9707-6428 \\ Danai Jattawa \\ https://orcid.org/0000-0003-1398-0282
}

Submitted Oct 28, 2018; Revised Nov 23, 2018; Accepted Feb 12, 2019
Objective: The objectives were to compare variance components, genetic parameters, prediction accuracies, and genomic-polygenic estimated breeding value (EBV) rankings for milk yield (MY) and fat yield (FY) in the Thai multibreed dairy population using five single nucleotide polymorphism (SNP) sets from GeneSeek GGP80K chip.

Methods: The dataset contained monthly MY and FY of 8,361 first-lactation cows from 810 farms. Variance components, genetic parameters, and EBV for five SNP sets from the GeneSeek GGP80K chip were obtained using a 2-trait single-step average-information restricted maximum likelihood procedure. The SNP sets were the complete SNP set (all available SNP; SNP100), top 75\% set (SNP75), top 50\% set (SNP50), top 25\% set (SNP25), and top 5\% set (SNP5). The 2-trait models included herd-year-season, heterozygosity and age at first calving as fixed effects, and animal additive genetic and residual as random effects. Results: The estimates of additive genetic variances for MY and FY from SNP subsets were mostly higher than those of the complete set. The SNP25 MY and FY heritability estimates (0.276 and 0.183) were higher than those from SNP75 (0.265 and 0.168), SNP50 (0.275 and 0.179), SNP5 (0.231 and 0.169), and SNP100 (0.251 and 0.159). The SNP25 EBV accuracies for MY and FY (39.76\% and 33.82\%) were higher than for SNP75 (35.01\% and 32.60\%), SNP50 (39.64\% and 33.38\%), SNP5 (38.61\% and 29.70\%), and SNP100 (34.43\% and 31.61\%). All rank correlations between SNP100 and SNP subsets were above 0.98 for both traits, except for SNP100 and SNP5 (0.93 for MY; 0.92 for FY).

Conclusion: The high SNP25 estimates of genetic variances, heritabilities, EBV accuracies, and rank correlations between SNP100 and SNP25 for MY and FY indicated that genotyping animals with SNP25 dedicated chip would be a suitable to maintain genotyping costs low while speeding up genetic progress for MY and FY in the Thai dairy population.

Keywords: Accuracy; Cattle; Genome; Imputation; Ranking; Tropics

\section{INTRODUCTION}

Genomic selection refers to selection of animals based on genomic estimated breeding values (GEBV) [1,2]. Current genomic selection procedures utilize a combination of phenotypes, pedigree, and genotype information to improve accuracy of genetic predictions [3]. An important advantage of genomic selection is that it can be implemented to evaluate economically important traits that are difficult to measure such as traits that are expensive to measure in a large number of animals (e.g., feed efficiency), expressed very late-in-life (e.g., length of productive life), and sex-limited traits (e.g., milk yield). In addition, because genomic selection can be performed early in life, it can decrease generation interval, increase 
intensity of selection, and reduce the cost of proving dairy bulls [1]. Genomic selection is currently widely used for dairy genetic evaluation in many countries. The Thai dairy genomicpolygenic evaluation for economically important traits started in 2015 [4]. Implementation of the genomic-polygenic evaluation system increased EBV accuracies for milk yield (MY) and fat yield (FY) from $5.2 \%$ to $7.2 \%$ in the Thai multibreed population [4]. Continued genotyping and selection of parents based on genomic-polygenic EBV is expected to accelerate the rate of genetic progress for MY and FY and other evaluated traits in this population.

Prices for high-density genotyping chips are still too high for widespread use in the multibreed dairy cattle population in Thailand. The current option in the Thai dairy population of genotyping sires and highly represented dams in the pedigree with high-density chips and the rest of the cow population with low-density chips may need to remain in place until a suitable cheaper and effective option is found. One such option would be to design low-density chips with small numbers of single nucleotide polymorphism (SNP) that account for a reasonable percentage of the genetic variation for the traits of interest. Use of these low-density assays containing selected SNPs could potentially be as effective as high-density chips for a fraction of the price $[5,6]$. Determination of an appropriate set of SNP needs to consider the genetic architecture of the traits of interest, population structure, amount of linkage disequilibrium, proportion of ancestors genotyped with high-density SNP genotypes, and genetic relationships between animals used to estimate SNP effects [5]. However, the optimal number of SNP for a low-density chip for dairy cattle in Thailand as well as an appropriate strategy for selecting these SNP have not been studied. Thus, the objectives of this research were to compare estimates of variance components, genetic parameters, accuracies of prediction, and rankings of genomic-polygenic animal EBV for MY and FY in the Thai multibreed dairy population computed using five sets of SNPs from GeneSeek GGP80K chip.

\section{MATERIALS AND METHODS}

\section{Animals, data and traits}

Cattle used in this research were from the Thai multibreed dairy population, a Holstein-upgraded population composed of purebred and crossbred cows, sires, and dams. Breeds represented in Thai dairy cattle are Holstein, Brahman, Jersey, Red Dane, Red Sindhi, Sahiwal, and Thai Native [7]. The largest breed fraction for most animals in the population is Holstein. Although, percentage Holstein per animal ranged from 46.9\% to $100 \%, 91 \%$ of cattle in the population was over $75 \% \mathrm{H}$ plus small percentages of other breeds. The dataset contained monthly test-day MYs and FYs of 8,361 first-lactation cows that calved from 1989 to 2014 . These cows were daughters of 1,210 sires and 6,992 dams located in 810 farms across five regions in Thailand (North, Northeastern, Western, Central, and Southern). Traits were 305-d first-lactation MY (kg) and 305-d first-lactation FY (kg). Test-day MYs were measured, and milk samples were taken from each individual cow once a month from calving until drying off. Cow test-day milk samples were sent to a laboratory (Artificial Insemination and Biotechnology Research Centre laboratory, Saraburi province, Thailand) to determine fat percentages. Test-day FYs were computed as the product of test-day MYs times test-day fat percentages. Monthly test-day MYs and FYs were used to compute MY and FY using the test-interval method $[8,9]$.

\section{Climate, management, and nutrition}

The majority of Thailand is hot and humid most of the year. Thailand's climate is highly influenced by the seasonal monsoon weather characterized by wind pattern changes and heavy precipitation. Seasons are classified as winter (November to February), summer (March to June), and rainy (July to October). Yearly means across regions and seasons range from $17^{\circ} \mathrm{C}$ to $36^{\circ} \mathrm{C}$ for temperature, 1,200 to $1,600 \mathrm{~mm} / \mathrm{yr}$ for rainfall, and $73 \%$ to $80 \%$ for relative humidity [10]. Cows were housed in open barns and milked twice a day (morning at 5 to $6 \mathrm{am}$; afternoon at 2 to $3 \mathrm{pm}$ ). Farmers used either a bucket system or a pipeline system for milking. Morning and afternoon raw milk was collected in bulk tanks before transporting it to a collection center owned by either dairy cooperative or a private organization. Cows were fed a combination of roughage and concentrate aimed at a rate of $1 \mathrm{~kg}$ of feed ( $16 \%$ protein) per $2 \mathrm{~kg}$ of milk. Roughage consisted mainly of fresh grasses including Guinea grass (Penicum maximum), Ruzi grass (Brachiaria ruziziensis), Napier grass (Pennisetum purpureum), and Para grass (Brachiaria mutica). Other sources of fiber were rice straw and agricultural byproducts (corn cobs, cassava leaves, corn silage).

\section{Samples and genotypes}

Blood or semen samples were collected from 2,661 animals (89 sires and 2,572 dams). Genomic DNA was extracted from semen samples using a GenElute Mammalian Genomic DNA Miniprep Kit (Sigma-Aldrich, St. Louis, MO, USA), whereas a MasterPure DNA Purification Kit (Epicentre Biotechnologies, Madison, WI, USA) was used for blood samples. Concentration and purity of DNA per sample was measured using a Thermo Fisher NanoDrop 2000 spectrophotometer (Thermo Fisher Science Inc., Wilmington, DE, USA). The minimum acceptable DNA concentration was $15 \mathrm{ng} / \mu \mathrm{L}$ with an absorbance ratio of 1.8 at $260 / 280 \mathrm{~nm}$.

The DNA samples were dried using a Freeze-dry machine for 12 hours Dried DNA samples of $50 \mu \mathrm{L}$ were airmailed to GeneSeek (Lincoln, NE 68521, USA) for genotyping with GeneSeek Genomic Profiler BeadChips (GGP). Budgetary 
restrictions determined the type of genotyping chip used for each DNA sample. The GeneSeek Genomic Profiler 80K chip (GGP80K) was used to genotype sires and highly represented cows in the pedigree $(\mathrm{n}=139)$, and lower density chips were used to genotype the remaining cows ([4];1,412 with GGP9K; 570 with GGP20K, and 540 with GGP26K). The numbers of SNP markers were 8,590 for the GGP9K, 19,616 for the GGP20K, 25,979 for the GGP26K, and 76,519 for the GGP80K. Nighty five percent of SNP from GGP20K, $47 \%$ of SNP from GGP20K, and 54\% of SNP from GGP26K were present in GGP80K. Cows genotyped with the three low-density GGP chips were imputed to GGP80K using FImpute 2.2 [11]. The genotype file included SNPs with call rates $\geq 90 \%$ and minor allele frequency $\geq 0.04$ from the 29 autosomes and the X chromosome. After these control restrictions, the genotype file contained 74,148 SNPs per genotyped animal.

\section{Estimation of variance components for five single nucleotide polymorphism sets}

The five SNP sets were defined in terms of the values of SNP variances for MY and FY [12] estimated with program POSTGSF90 (a member of the BLUPF90 Family of Programs) [13]. Firstly, a 2-trait single-step genomic-polygenic model $[3,14]$ was used to estimate variance components for MY and FY using the complete dataset (phenotypes, pedigree, and genotypes) with program AIREMLF90 [15]. Secondly, SNP variances for MY and FY were computed using program POSTGSF90 and ordered from largest to smallest. Then, the following 5 SNP sets (Table 1) were defined: i) complete SNP set (SNP100; 76,519 SNPs); ii) top 75\% set (SNP75; 57,390 SNPs); iii) top $50 \%$ set (SNP50; 38,260 SNPs); iv) top 25\% set (SNP25; 19,130 SNPs); and v) top 5\% set (SNP5; 3,826 SNPs).

Estimates of variance components for MY and FY for the five sets of genotypes were computed with AIREMLF90 [15] using the same 2-trait genomic-polygenic model. This model contained herd-year-season, heterozygosity of the cow, and age at first calving as fixed effects, and animal additive genetic and residual as random effects. The mean of the animal additive genetic and the residual effects was assumed to be zero. The variance of the animal additive genetic effects was equal to $\mathrm{H} \otimes \mathrm{V}_{\mathrm{a}}$, where $\mathrm{H}$ is a genomic-polygenic relationship matrix among all animals in the pedigree (with and without genotypes; [16]), and $V_{a}$ is a $2 \times 2$ matrix of additive genetic variances and covariances between MY and FY. The variance of residual effects was equal to $\mathrm{I} \otimes \mathrm{V}_{e}$, where $\mathrm{I}$ is an identity matrix, and $\mathrm{V}_{e}$ is a $2 \times 2$ matrix of environmental variances and covariances between MY and FY. The convergence criterion for program AIREMLF90 was $10^{-12}$. The estimates of additive genetic and environmental variances and covariances at convergence for MY and FY were used to compute phenotypic variances and covariances, heritabilities, and genetic,
Table 1. Number of SNP per chromosome and total for the five SNP sets

\begin{tabular}{|c|c|c|c|c|c|}
\hline \multirow{2}{*}{ Chromosomes } & \multicolumn{5}{|c|}{ SNP sets ${ }^{1)}$} \\
\hline & SNP100 & SNP75 & SNP50 & SNP25 & SNP5 \\
\hline 1 & 4,512 & 3,286 & 2,043 & 959 & 166 \\
\hline 2 & 3,914 & 2,765 & 1,775 & 843 & 157 \\
\hline 3 & 3,566 & 2,604 & 1,692 & 804 & 165 \\
\hline 4 & 3,398 & 2,617 & 1,774 & 907 & 165 \\
\hline 5 & 3,528 & 2,671 & 1,755 & 868 & 163 \\
\hline 6 & 3,399 & 2,587 & 1,748 & 884 & 163 \\
\hline 7 & 3,209 & 2,437 & 1,686 & 862 & 176 \\
\hline 8 & 3,248 & 2,505 & 1,704 & 888 & 170 \\
\hline 9 & 3,085 & 2,356 & 1,599 & 840 & 152 \\
\hline 10 & 3,007 & 2,313 & 1,564 & 810 & 186 \\
\hline 11 & 3,094 & 2,390 & 1,668 & 893 & 225 \\
\hline 12 & 2,662 & 2,073 & 1,422 & 726 & 156 \\
\hline 13 & 2,468 & 1,909 & 1,268 & 654 & 123 \\
\hline 14 & 2,495 & 1,949 & 1,364 & 745 & 180 \\
\hline 15 & 2,579 & 1,970 & 1,315 & 664 & 167 \\
\hline 16 & 2,471 & 1,903 & 1,320 & 696 & 143 \\
\hline 17 & 2,229 & 1,761 & 1,187 & 603 & 140 \\
\hline 18 & 2,056 & 1,567 & 1,072 & 544 & 118 \\
\hline 19 & 2,012 & 1,563 & 1,068 & 565 & 128 \\
\hline 20 & 2,228 & 1,573 & 1,038 & 484 & 84 \\
\hline 21 & 2,220 & 1,529 & 990 & 460 & 74 \\
\hline 22 & 1,894 & 1,262 & 748 & 325 & 49 \\
\hline 23 & 1,732 & 1,210 & 768 & 348 & 71 \\
\hline 24 & 1,936 & 1,371 & 888 & 420 & 67 \\
\hline 25 & 1,413 & 984 & 640 & 288 & 38 \\
\hline 26 & 1,618 & 1,186 & 762 & 365 & 67 \\
\hline 27 & 1,440 & 1,131 & 768 & 387 & 80 \\
\hline 28 & 1,488 & 1,180 & 813 & 410 & 69 \\
\hline 29 & 1,596 & 1,213 & 821 & 396 & 89 \\
\hline X & 2,022 & 1,525 & 1,000 & 492 & 95 \\
\hline Total & 76,519 & 57,390 & 38,260 & 19,130 & 3,826 \\
\hline
\end{tabular}

SNP, single nucleotide polymorphism.

1) The SNP sets were the complete SNP set: SNP100, all available SNP; SNP75, top $75 \%$ set; SNP50, top 50\% set; SNP25, top 25\% set; SNP5, top 5\% set.

environmental, and phenotypic correlations using the usual expressions. Standard errors of additive genetic and environmental variances and covariances were computed as square roots of diagonal elements of the inverse of the average information matrix computed at convergence. Standard deviations of phenotypic variances and covariances, heritabilities, and genetic, environmental, and phenotypic correlations were computed with a repeated sampling procedure [17] using a set of 5,000 samples.

\section{Animal estimated breeding values, accuracies, and rankings}

Animal EBV for MY and FY for the five SNP sets (SNP5, SNP25, SNP50, SNP75, and SNP100) were computed using the estimates of variance components at convergence for each set of genotypes. The EBV accuracies for each trait were ob- 
tained as the correlation between EBV and true breeding values computed using the formula: $\sqrt{1-\frac{P E V}{\sigma_{a}^{2}}} \times 100$, where $\mathrm{PEV}$ is the prediction error variance (square of the standard error of prediction) and $\widehat{\sigma_{a}^{2}}$ is the estimate of the additive genomic-polygenic variance for each SNP set. After computing animal EBV for MY and FY with the five SNP sets, animal EBV were ranked from largest to smallest for MY and from smallest to largest for FY. Subsequently, animal rankings from five SNP sets were compared using the Spearman's rank correlation procedure of SAS 9.0 (SAS Inst. Inc., Cary, NC, USA).

\section{RESULTS AND DISCUSSION}

Variances components, heritabilities, and correlations Estimates of variances and covariances for MY and FY using genomic-polygenic models with five sets of SNP are shown in Table 2 for additive genetic effects, Table 3 for environmental effects, and in Table 4 for phenotypic effects. Similar estimates of additive genetic, environmental, and phenotypic variances and covariances for MY and FY were obtained for the five sets of SNP. Estimates of additive genetic variances ranged from $146,440.00 \pm 20,231.00 \mathrm{~kg}^{2}$ (SNP5) to $178,510.00 \pm 26,620.00$ $\mathrm{kg}^{2}$ (SNP50) for MY and from $201.54 \pm 60.91 \mathrm{~kg}^{2}$ (SNP100) to $231.49 \pm 57.71 \mathrm{~kg}^{2}$ (SNP25) for FY, and additive genetic covariances ranged from $4,041.40 \pm 813.25 \mathrm{~kg} \times \mathrm{kg}$ (SNP5) to $4,758.10 \pm 984.95 \mathrm{~kg} \times \mathrm{kg}$ (SNP25). Estimates of environmental variances ranged from $467,000.00 \pm 22,641.00 \mathrm{~kg}^{2}$ (SNP25) to $488,910.00 \pm 19,276.00 \mathrm{~kg}^{2}$ (SNP5) for MY and from 1,033.30 $\pm 57.18 \mathrm{~kg}^{2}$ (SNP25) to $1,065.90 \pm 60.37 \mathrm{~kg}^{2}$ (SNP100) for FY, and environmental covariances ranged from $14,780.00 \pm 945.30$ $\mathrm{kg} \times \mathrm{kg}$ (SNP25) to $15,590.00 \pm 1,046.00 \mathrm{~kg} \times \mathrm{kg}$ (SNP100). Estimates of phenotypic variances ranged from $635,580.00 \pm$ $13,307.00 \mathrm{~kg}^{2}$ (SNP5) to $650,520.00 \pm 13,794.00 \mathrm{~kg}^{2}$ (SNP100) for MY and from $1,257.00 \pm 33.25 \mathrm{~kg}^{2}$ (SNP5) to $1,267.20 \pm$ $33.61 \mathrm{~kg}^{2}$ (SNP75) for FY, and phenotypic covariances ranged from $19,286.00 \pm 566.53 \mathrm{~kg} \times \mathrm{kg}$ (SNP5) to $19,678 \pm 580.44 \mathrm{~kg} \times \mathrm{kg}$ (SNP75).

Estimates of additive genetic variances and covariances for MY and FY were higher for models with SNP75 (variances:

Table 2. Additive genetic variances and covariances for MY and FY estimated with five SNP sets using genomic-polygenic models

\begin{tabular}{|c|c|c|c|c|c|c|c|c|c|c|}
\hline \multirow{2}{*}{$\begin{array}{l}\text { Variance } \\
\text { component }\end{array}$} & \multicolumn{10}{|c|}{ SNP sets ${ }^{1)}$} \\
\hline & SNP100 & SE & SNP75 & SE & SNP50 & SE & SNP25 & SE & SNP5 & SE \\
\hline $\operatorname{Var}\left(\mathrm{MY}, \mathrm{kg}^{2}\right)$ & $163,320.00$ & $28,138.00$ & $172,120.00$ & $27,651.00$ & $178,510.00$ & $26,620.00$ & $177,080.00$ & $24,794.00$ & $146,440.00$ & $20,231.00$ \\
\hline $\operatorname{Cov}(M Y, F Y, k g \times k g)$ & $4,088.40$ & $1,094.10$ & $4,430.80$ & $1,081.60$ & $4,694.80$ & $1,049.60$ & $4,758.10$ & 984.95 & $4,041.40$ & 813.25 \\
\hline $\operatorname{Var}\left(\mathrm{FY}, \mathrm{kg}^{2}\right)$ & 201.54 & 60.91 & 213.55 & 60.71 & 227.67 & 60.01 & 231.49 & 57.71 & 212.37 & 50.40 \\
\hline
\end{tabular}

MY, milk yield; FY, fat yield; SNP, single nucleotide polymorphism; SE, standard error.

1) SNP100, complete SNP set (76,519 SNPs); SNP75, top 75\% SNP (57,390 SNPs); SNP50, top 50\% SNP (38,260 SNPs); SNP25, top 25\% SNP (19, 130 SNPs); SNP5 = top 5\% $\operatorname{SNP}(3,826$ SNPS).

Table 3. Environmental variances and covariances for MY and FY estimated with five SNP sets using genomic-polygenic models

\begin{tabular}{|c|c|c|c|c|c|c|c|c|c|c|}
\hline \multirow{2}{*}{$\begin{array}{l}\text { Variance } \\
\text { component }\end{array}$} & \multicolumn{10}{|c|}{ SNP sets ${ }^{1)}$} \\
\hline & SNP100 & SE & SNP75 & SE & SNP50 & SE & SNP25 & SE & SNP5 & SE \\
\hline $\operatorname{Var}\left(\mathrm{MY}, \mathrm{kg}^{2}\right)$ & $486,970.00$ & $25,730.00$ & $477,830.00$ & $25,161.00$ & $469,800.00$ & $24,179.00$ & $467,000.00$ & $22,641.00$ & $488,910.00$ & $19,276.00$ \\
\hline $\operatorname{Cov}(M Y, F Y, k g \times k g)$ & $15,590.00$ & $1,046.00$ & $15,251.00$ & $1,029.70$ & $14,950.00$ & 998.36 & $14,780.00$ & 945.30 & $15,248.00$ & 818.88 \\
\hline $\operatorname{Var}\left(\mathrm{FY}, \mathrm{kg}^{2}\right)$ & $1,065.90$ & 60.37 & $1,054.40$ & 59.95 & $1,039.90$ & 59.08 & $1,033.30$ & 57.18 & $1,045.40$ & 51.53 \\
\hline
\end{tabular}

$M Y$, milk yield; $F Y$, fat yield; SNP, single nucleotide polymorphism; $S E$, standard error.

1) SNP100, complete SNP set (76,519 SNPs); SNP75, top 75\% SNP (57,390 SNPs); SNP50, top 50\% SNP (38,260 SNPs); SNP25, top 25\% SNP (19,130 SNPs); SNP5, top 5\% SNP (3,826 SNPs).

Table 4. Phenotypic variances and covariances for MY and FY estimated with five SNP sets using genomic-polygenic models

\begin{tabular}{|c|c|c|c|c|c|c|c|c|c|c|}
\hline \multirow{2}{*}{$\begin{array}{l}\text { Variance } \\
\text { component }\end{array}$} & \multicolumn{10}{|c|}{ SNP sets ${ }^{1)}$} \\
\hline & SNP100 & $\mathrm{SD}^{2)}$ & SNP75 & SD & SNP50 & SD & SNP25 & SD & SNP5 & SD \\
\hline $\operatorname{Var}\left(\mathrm{MY}, \mathrm{kg}^{2}\right)$ & $650,520.00$ & $13,794.00$ & $650,190.00$ & $13,796.00$ & $648,550.00$ & $13,748.00$ & $644,310.00$ & $13,612.00$ & $635,580.00$ & $13,307.00$ \\
\hline $\operatorname{Cov}(M Y, F Y, k g \times k g)$ & $19,674.00$ & 580.06 & $19,678.00$ & 580.44 & $19,641.00$ & 579.37 & $19,534.00$ & 575.38 & $19,286.00$ & 566.53 \\
\hline $\operatorname{Var}\left(\mathrm{FY}, \mathrm{kg}^{2}\right)$ & $1,266.70$ & 33.57 & $1,267.20$ & 33.61 & $1,266.80$ & 33.62 & $1,264.00$ & 33.52 & $1,257.00$ & 33.25 \\
\hline
\end{tabular}

$M Y$, milk yield; FY, fat yield; SNP, single nucleotide polymorphism; SD, standard deviation.

1) SNP100, complete SNP set (76,519 SNPs); SNP75, top 75\% SNP (57,390 SNPs); SNP50, top 50\% SNP (38,260 SNPs); SNP25, top 25\% SNP (19, 130 SNPs); SNP5, top 5\% SNP (3,826 SNPs).

${ }^{2)}$ Repeated sampling approach of Meyer and Houle [17]. 
5.39\% for MY, 5.96\% for FY; covariances: 8.37\%), SNP50 (variances: $9.30 \%$ for MY, $12.97 \%$ for FY; covariances: $14.83 \%$ ), SNP25 (variances: $8.43 \%$ for MY, $14.86 \%$ for FY; covariances: $16.38 \%$ ) than those estimated using SNP100. However, the model with SNP5 yielded lower estimates of additive genetic variance for MY $(-10.34 \%)$ and covariance between MY and FY $(-1.15 \%)$, and higher estimate of additive genetic variance for FY (5.37\%) than the model with SNP100. Conversely, environmental variances and covariances for MY and FY were lower for the model with SNP75 (variances: $-1.88 \%$ for MY, $-1.08 \%$ for FY; covariance: $-2.17 \%$ ), SNP50 (variances: $-3.53 \%$ for MY, $-2.44 \%$ for FY; covariance: $-4.11 \%)$, SNP25 (variances: $-4.10 \%$ for MY, $-3.06 \%$ for FY; covariance: $-5.20 \%$ ) than those estimated using SNP100. The model with SNP5 produced a higher environmental variance for MY $(0.40 \%)$, but a lower environmental variance for FY $(-1.92 \%)$ and covariance between MY and FY (-2.19\%) than the corresponding estimates from the model with SNP100. Lastly, estimates of phenotypic variances and covariances for MY and FY from models with SNP75, SNP50, and SNP25 were nearly identical (differences were near zero or below one percent) to the corresponding values from model with SNP100, whereas the corresponding differences for the model with SNP5 were all negative and mostly higher than one percent (variances: $-2.30 \%$ for MY, $-0.77 \%$ for FY; covariance: $-1.97 \%$ ).

The slightly higher additive genetic variances and covariances but lower environmental variances and covariances for MY and FY obtained with SNP75, SNP50, and SNP25 than with the complete SNP set indicated that these SNP subsets may have been able to more accurately accounted for MY and FY additive variability in this population than the complete SNP set. This may have occurred because the SNP markers in these subsets were on the average more closely associated with quantitative trait locus (QTL) affecting MY and FY than the complete set of SNP [18].

Heritabilities and additive genetic, environmental, and phenotypic correlations between MY and FY are presented in Table 5. Heritability estimates ranged from $0.231 \pm 0.030$ (SNP5) to $0.276 \pm 0.039$ (SNP25) for MY and from $0.159 \pm 0.047$
(SNP100) to $0.183 \pm 0.044$ (SNP25) for FY. The SNP25 MY and FY heritability estimates were slightly higher $(0.4 \%$ to $20 \%$ ) than those from SNP100, SNP75, SNP50, and SNP5. These differences among heritability estimates across SNP sets may be related to differences in linkage disequilibria between the SNP in each set and QTL affecting MY and FY determined by number of SNP and proximity of SNP in each set to MY and FY QTL [18]. Higher SNP25 heritability estimates for MY and FY indicated that faster selection responses for these traits could be expected with SNP25 than with SNP100, SNP75, SNP50, and SNP5 in the Thai dairy population.

Heritability estimates for MY and FY across the five SNP sets were similar to values estimated in previous studies in the Thai dairy population using various SNP sets ( 0.19 to 0.26 for MY; 0.15 to 0.18 for FY [4]). Heritabilities for MY in the Thai dairy population were within the range of heritability estimated for MY in various Holstein populations in temperate regions $(0.25$ to $0.30[6,19,20])$, but somewhat higher than an estimate in Holstein under tropical conditions in Brazil (0.13 [21]). Conversely, heritability estimates for FY were somewhat lower than values obtained for Holstein in temperate regions $(0.25$ to $0.30[19,20,22])$

Estimates of additive genetic, environmental and phenotypic correlations between MY and FY across the five sets of SNP were virtually identical (Table 5). Correlation estimates between MY and FY ranged from $0.718 \pm 0.115$ (SNP100) to $0.748 \pm 0.087$ (SNP25) for additive genetic, from $0.673 \pm 0.023$ (SNP25) to $0.684 \pm 0.023$ (SNP100) for environmental, and from $0.682 \pm 0.009$ (SNP5) to $0.686 \pm 0.010$ (SNP75) for phenotypic. The positive genetic correlations between MY and FY obtained here were similar to values previously reported for this Thai dairy population (0.66 to 0.79 [4]), and in agreement with estimates for Holstein in other tropical $(0.70$ to $0.75[23,24])$, and in temperate regions $(0.70$ to $0.88[25,26])$.

The comparable or slightly higher additive genetic variances and heritabilities for MY and FY from SNP25, SNP50, and SNP75 than from SNP100 indicated that selecting a subset of SNP genotypes with the approach used here would be

Table 5. Heritabilities and genetic, environmental, and phenotypic correlations between MY and FY estimated with five SNP sets using genomic-polygenic models

\begin{tabular}{lcccccccccc}
\hline \multirow{2}{*}{ Parameter } & \multicolumn{10}{c}{ SNP sets ${ }^{1)}$} \\
\cline { 2 - 10 } & SNP100 & SD $^{2)}$ & SNP75 & SD & SNP50 & SD & SNP25 & SD & SNP5 & SD \\
\hline Heritability (MY) & 0.251 & 0.041 & 0.265 & 0.040 & 0.275 & 0.039 & 0.276 & 0.036 & 0.231 & 0.030 \\
Heritability (FY) & 0.159 & 0.047 & 0.168 & 0.047 & 0.179 & 0.046 & 0.183 & 0.045 & 0.169 & 0.039 \\
Genetic correlation (MY, FY) & 0.718 & 0.115 & 0.736 & 0.102 & 0.741 & 0.094 & 0.748 & 0.087 & 0.674 & 0.020 \\
Environmental correlation (MY, FY) & 0.684 & 0.023 & 0.679 & 0.024 & 0.676 & 0.024 & 0.673 & 0.023 & 0.674 & 0.020 \\
Phenotypic correlation (MY, FY) & 0.685 & 0.010 & 0.686 & 0.010 & 0.685 & 0.010 & 0.684 & 0.010 & 0.682 & 0.010 \\
\hline
\end{tabular}

MY, milk yield; FY, fat yield; SNP, single nucleotide polymorphism; SD, standard deviation.

1) SNP100, complete SNP set (76,519 SNPs); SNP75, top 75\% SNP (57,390 SNPs); SNP50, top 50\% SNP (38,260 SNPs); SNP25, top 25\% SNP (19, 130 SNPs); SNP5, top 5\% SNP (3,826 SNPs).

2) Repeated sampling approach of Meyer and Houle [17]. 
a reasonable alternative to increase the effectiveness of genomic-polygenic evaluation and selection in the Thai dairy population. However, reducing SNP genotypes to 3,826 SNP (SNP5) or $5 \%$ of the SNP in the GGP80K chip would yield lower variance component and heritability estimates than with the SNP25, SNP50, and SNP75 subsets, or with the complete SNP set. Further, the highest genetic variance component and heritability estimates for MY and FY obtained with SNP25 indicated that higher EBV prediction accuracies and selection responses for these traits would be achieved using a genomic- polygenic model with SNP25 than with SNP100, SNP75, SNP50, and SNP5.

\section{Accuracy of genomic-polygenic estimated breeding} values and animal rankings with five single nucleotide polymorphism sets

The accuracies genomic-polygenic EBV for MY and FY with the five sets of SNP genotypes (SNP100, SNP75, SNP50, SNP25, and SNP5) are shown in Figure 1. The SNP25 had the highest mean EBV accuracy for all animals (39.76\% for
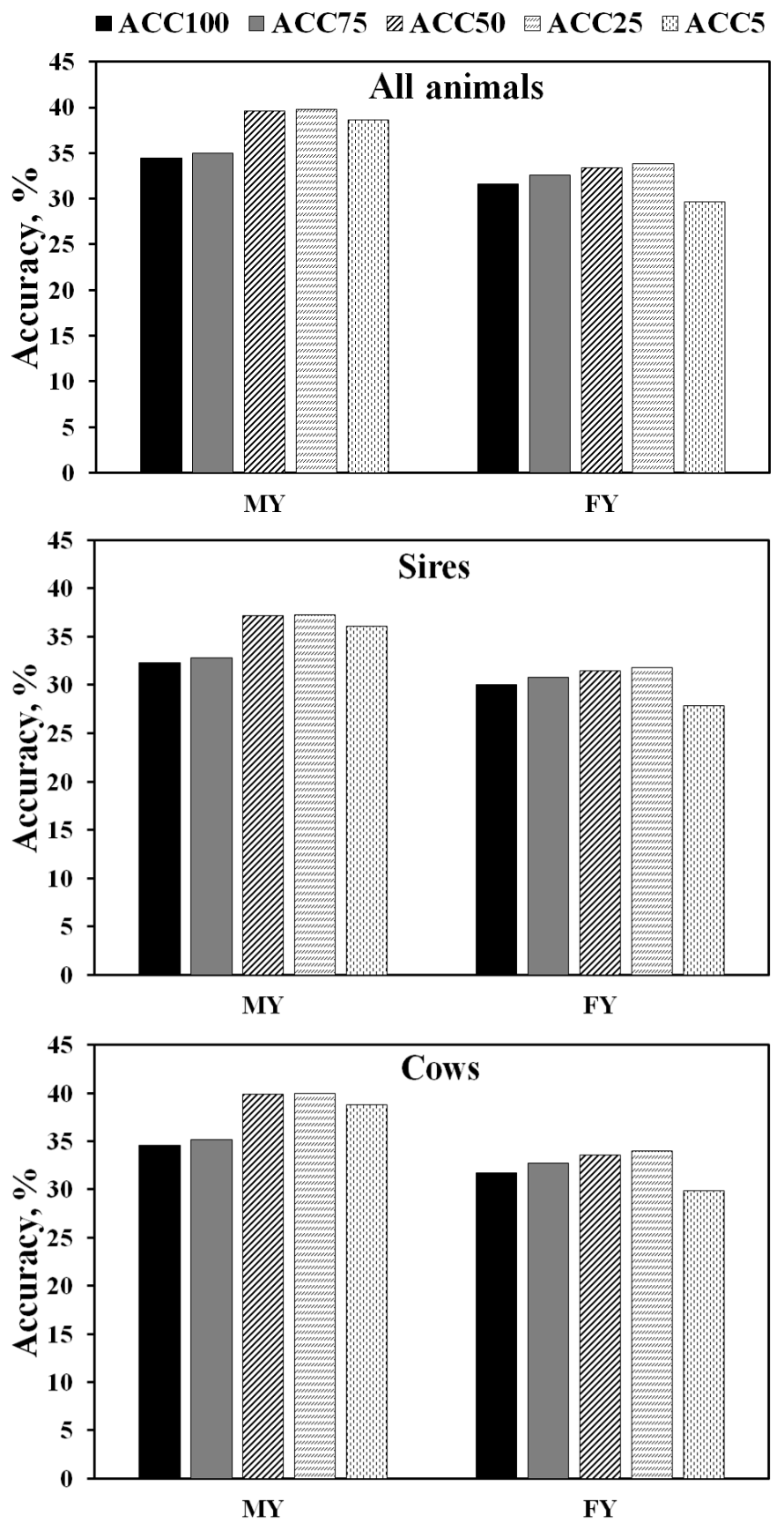

Figure 1. Accuracy of estimated breeding value for MY and FY estimated with five single nucleotide polymorphism sets using genomic-polygenic models. MY, milk yield; FY, fat yield. 
MY and 33.82\% for FY), sires (37.30\% for MY and 31.85\% for FY), and cows (39.98\% for MY and 33.99\% for FY). Conversely, SNP100 yielded the lowest mean EBV accuracies for all animals (35.18\% for MY and 28.36\% for FY), sires (33.12\% for MY and 26.94\% for FY), and cows (35.36\% for MY and 28.49\% for FY). Further, the mean EBV accuracies from the four SNP subsets (SNP75, SNP50, SNP25, SNP5) were mostly higher than the mean EBV accuracy from the complete SNP set (SNP100) for all animals, sires, and cows. The percentage superiority of the mean EBV accuracies of SNP75, SNP50, SNP25, and SNP5 over SNP100 for MY were 0.58\%, 5.21\%, $5.34 \%$, and $4.18 \%$ for all animals, $0.54 \%, 4.92 \%, 5.01 \%$, and $3.76 \%$ for sires, and $0.58 \%, 5.24 \%, 5.36 \%$, and $4.21 \%$ for cows. Similarly, the percentage superiority of the mean EBV accuracies of SNP75, SNP50, and SNP25 over SNP100 for FY were $0.98 \%, 1.77 \%$, and $2.21 \%$ for all animals, $0.81 \%, 1.48 \%$, and $1.84 \%$ for sires, and $0.99 \%, 1.80 \%$, and $2.34 \%$ for cows. However, the mean EBV accuracies of SNP5 for FY were slightly lower $(-1.91 \%$ for all animals, $-2.18 \%$ for sires, and $-1.89 \%$ for cows) than those of SNP100. The mostly higher mean EBV accuracies of the four SNP subsets were largely due to the higher MY and FY additive genetic variances explained by these SNP subsets than by the complete SNP set. Further, the fact that SNP25 yielded the highest mean EBV accuracy indicated that choosing the top 25\% of SNP from GeneSeek GGP80K based on percent of additive genetic variance explained for MY and FY (19,130 SNP) would be a suitable alternative to the complete SNP set for genomic-polygenic evaluation and selection in the Thai dairy multibreed population.

The higher mean EBV accuracies obtained with four GGP80K subsets than with the complete SNP set supported the findings from previous research in dairy [5,27-29] and in beef cattle [30] that SNP subsets can yield comparable or higher levels of EBV accuracy than complete SNP sets while lowering genotyping costs.

Pairwise Spearman rank correlations between MY and FY EBV from of the complete SNP set and each of the four SNP subsets are shown in Table 6 . All rank correlations between

Table 6. Spearman rank correlations between SNP100 and SNP75, SNP100 and SNP50, SNP100 and SNP25, and SNP100 and SNP5 for MY and FY

\begin{tabular}{lcccc}
\hline & \multicolumn{4}{c}{ Rank correlation $^{1)}$} \\
\cline { 2 - 5 } Trait & $\begin{array}{c}\text { SNP100, } \\
\text { SNP75 }\end{array}$ & $\begin{array}{c}\text { SNP100, } \\
\text { SNP50 }\end{array}$ & $\begin{array}{c}\text { SNP100, } \\
\text { SNP25 }\end{array}$ & $\begin{array}{c}\text { SNP100, } \\
\text { SNP5 }\end{array}$ \\
\hline MY & 0.997 & 0.991 & 0.976 & 0.926 \\
FY & 0.997 & 0.990 & 0.976 & 0.919 \\
\hline
\end{tabular}

SNP, single nucleotide polymorphism; MY, milk yield; FY, fat yield.

1) SNP100, complete SNP set (76,519 SNPs); SNP75, top 75\% SNP (57,390 SNPs); SNP50, top 50\% SNP (38,260 SNPs); SNP25, top 25\% SNP (19,130 SNPs); SNP5, top 5\% SNP (3,826 SNPs);

All Spearman rank correlations were significant $(p<0.0001)$.
SNP100 and the four SNP subsets were above $0.98(\mathrm{p}<0.0001)$ for both traits, except for the correlation between SNP100 and SNP5 (MY, 0.93; FY, 0.92; p<0.0001). Rank correlations between SNP75 and SNP100 and between SNP50 and SNP100 for MY and FY were above 0.99 ( $\mathrm{p}<0.0001)$, followed closely by rank correlations between SNP25 and SNP100 for MY (0.98; $\mathrm{p}<0.0001)$. Rank correlations indicated a high degree of agreement between EBV from genomic-polygenic evaluations with the four SNP subsets and the complete SNP set. The high SNP25 estimates of genetic variances, heritabilities, EBV accuracies, and rank correlations between SNP100 and SNP25 for MY and FY indicated that SNP25 would be expected to produce higher selection responses for MY and FY than any of the other SNP subsets and the complete GeneSeek 80K set. This indicates that a strategy to keep genotyping costs reasonably low while speeding up genetic progress for MY and FY would be to genotype animals in the Thai multibreed dairy population with a dedicated chip constructed with the subset of SNP markers in the SNP25 set. Thai dairy producers could decrease their genotyping costs before the utilization of a dedicated chip likely without reducing their ability to select replacement animals based on genomic-polygenic EBV by utilizing lower-density commercial genotyping chips.

\section{CONCLUSION}

Estimates of additive genetic variances, heritabilities, and EBV accuracies for MY and FY from genomic-polygenic models with SNP subsets were higher than those with complete SNP set. Genomic-polygenic evaluation with SNP25 had the highest estimates of additive genetic variances, heritabilities, and EBV accuracies for MY and FY. Further, genomic-polygenic EBV obtained using SNP subsets and complete SNP set had high rank correlations. Thus, utilization of the SNP25 set would be a suitable alternative to reduce genotyping costs and increase selection response for MY and FY in this dairy population.

\section{CONFLICT OF INTEREST}

We certify that there is no conflict of interest with any financial organization regarding the material discussed in the manuscript.

\section{ACKNOWLEDGMENTS}

This research was a part of the project for development of a dairy genetic-genomic evaluation system in Thailand (P-1100116) funded by the National Science and Technology Development Agency, Kasetsart University, and the Dairy Farming Promotion Organization, and partly supported by the Kasetsart University Research and Development Institute 
(S-K[KS]1.58) through the project entitled Increasing genetic potential of Thai cattle using genomic selection. The authors would like to thank the National Science and Technology Development Agency, University and Industry Research Collaboration (NUI-RC) for awarding a scholarship to the first author, Kasetsart University (Bangkok, Thailand) and the University of Florida (Gainesville, Florida, USA) for their support of the authors' long-term research collaboration, the Tropical Animal Genetic Unit (TAGU) for the dataset, and the Thai dairy farmers for their contributions to this project.

\section{REFERENCES}

1. Meuwissen TH, Hayes BJ, Goddard ME. Prediction of total genetic value using genome-wide dense marker maps. Genetics 2001;157:1819-29.

2. Hayes B, Bowman P, Chamberlain A, Verbyla K, Goddard M. Accuracy of genomic breeding values in multi-breed dairy cattle populations. Genet Sel Evol 2009;41:51. https://doi. org/10.1186/1297-9686-41-51

3. Aguilar I, Misztal I, Johnson DL, Legarra A, Tsuruta S, Lawlor TJ. Hot topic: A unified approach to utilize phenotypic, full pedigree, and genomic information for genetic evaluation of Holstein final score. J Dairy Sci 2010;93:743-52. https:// doi.org/10.3168/jds.2009-2730

4. Jattawa D, Elzo MA, Koonawootrittriron S, Suwanasopee T. Comparison of genetic evaluations for milk yield and fat yield using a polygenic model and three genomic-polygenic models with different sets of SNP genotypes in Thai multibreed dairy cattle. Livest Sci 2015;181:58-64. https:/doi.org/10.1016/ j.livsci.2015.10.008

5. Weigel KA, de los Campos G, González-Recio O, et al. Predicting ability of direct genomic values for lifetime net merit of Holstein sires using selected subsets of single nucleotide polymorphism markers. J Dairy Sci 2009;92:5248-57. https:// doi.org/10.3168/jds.2009-2092

6. Moser G, Khatkar MS, Hayes BJ, Raadsma HW. Accuracy of direct genomic values in Holstein bulls and cows using subsets of SNP markers. Genet Sel Evol 2010;42:37. https:// doi.org/10.1186/1297-9686-42-37

7. Koonawootrittriron S, Elzo MA, Thongprapi T. Genetic trends in a Holstein $\mathrm{x}$ other breeds multibreed dairy population in Central Thailand. Livest Sci 2009;122:186-92. https:// doi.org/10.1016/j.livsci.2008.08.013

8. Sargent FD, Lytton VH, Wall OG. Test interval method of calculating dairy herd improvement association records. J Dairy Sci 1968;51:170-9. https://doi.org/10.3168/jds.S00220302(68)86943-7

9. Koonawootrittriron S, Elzo MA, Tumwasorn S, Sintala W. Prediction of 100-d and 305-d milk yields in a multibreed dairy herd in Thailand using monthly test-day records. Thai J Agric Sci 2001;34:163-74.
10.TMD. The climate of Thailand. Bangkok, Thailand: Thai Meteorological Department. Available from: https://www.tmd. go.th/en/archive/thailand_climate.pdf

11.Sargolzaei M, Chesnais JP, Schenkel FS. A new approach for efficient genotype imputation using information from relatives. BMC Genomics 2014;15:478. https://doi.org/10.1186/14712164-15-478

12. Wang H, Misztal I, Aguilar I, Legarra A, Muir WM. Genomewide association mapping including phenotypes from relatives without genotypes. Genet Res 2012;94:73-83. https:// doi.org/10.1017/S0016672312000274

13. Misztal I, Tsuruta S, Lourenco D, Aguilar I, Legarra A, Vitezica Z. Manual for BLUPF90 family of programs. Athens, GA, USA: University of Georgia, 2018 [cited 2018 June 19]. Available from: http://nce.ads.uga.edu/wiki/lib/exe/fetch.php?media= blupf90_all7.pdf

14. Misztal I, Legarra A, Aguilar I. Computing procedures for genetic evaluation including phenotypic, full pedigree, and genomic information. J Dairy Sci 2009;92:4648-55. https:// doi.org/10.3168/jds.2009-2064

15. Tsuruta S. Average Information REML with several options including EM-REML and heterogeneous residual variances; 2014 [cited 2018 June 19]. Available from: http://nce.ads.uga. edu/wiki/doku.php?id=application_programs

16.Legarra A, Aguilar I, Misztal I. A relationship matrix including full pedigree and genomic information. J Dairy Sci 2009;92: 4656-63. https://doi.org/10.3168/jds.2009-2061

17. Meyer K, Houle D. Sampling based approximation of confidence intervals for functions of genetic covariance matrices. In: Proceedings of the Association for the Advancement of Animal Breeding and Genetics 2013; 2013 August 20-23: Napier, New Zealand. 2013. p. 523-6.

18. Haile-Mariam M, Nieuwhof GJ, Beard KT, Konstatinov KV, Hayes BJ. Comparison of heritabilities of dairy traits in Australian Holstein-Friesian cattle from genomic and pedigree data and implications for genomic evaluations. J Anim Breed Genet 2013;130:20-31. https://doi.org/10.1111/j.1439-0388. 2013.01001.X

19. VanRaden PM, Van Tassell CP, Van Tassell GR, et al. Invited review: Reliability of genomic predictions for North American Holstein bulls. J Dairy Sci 2009;92:16-24. https://doi.org/10. 3168/jds.2008-1514

20.Sun C, VanRaden PM, Cole JB, Connell JRO. Improvement of prediction ability for genomic selection of dairy cattle by including dominance effects. PLoS ONE 2014;9:e103934. https://doi.org/10.1371/journal.pone.0103934

21.Petrini J, Iung LHS, Rodriguez MAP, et al. Genetic parameters for milk fatty acids, milk yield and quality traits of a Holstein cattle population reared under tropical conditions. J Anim Breed Genet 2016;133:384-95.

22. Gao H, Christensen OF, Madsen P, et al. Comparison on genomic predictions using three GBLUP methods and two single- 
step blending methods in the Nordic Holstein population. Genet Sel Evol 2012;44:8. https://doi.org/10.1186/1297-968644-8

23. Okeno TO, Kosgey IS, Kahi AK. Genetic evaluation of breeding strategies for improvement of dairy cattle in Kenya. Trop Anim Health Prod 2010:42;1073-9. https://doi.org/10.1007/s11250010-9528-Z

24.Mokhtari MS, Moradi SM, Nejati JA, Rosa GJM. Genetic relationship between heifers and cows fertility and milk yield traits in first-parity Iranian Holstein dairy cows. Livest Sci 2015;182:76-82. https://doi.org/10.1016/j.livsci.2015.10.026

25.Pritchard T, Coffey M, Mrode R, Wall E. Genetic parameters for production, health, fertility and longevity traits in dairy cows. Animal 2013;7:34-46. https://doi.org/10.1017/S1751 731112001401

26.Sneddon NW, Lopez-Villalobos N, Davis SR, Hickson RE, Shalloo L. Genetic parameters for milk components including lactose from test day records in the New Zealand dairy herd. New Zealand J Agric Res 2015;58:97-107. https://doi.org/
10.1080/00288233.2014.978482

27.Szyda J, Żukowski K, Kamiński S, Żarnecki A. Testing different single nucleotide polymorphism selection strategies for prediction of genomic breeding values in dairy cattle based on low density panels. Czech J Anim Sci 2013;58:136-45.

28. VanRaden PM, Tooker ME, O'Connell JR, Cole JB, Bickhart DM. Selecting sequence variants to improve genomic predictions for dairy cattle. Genet Sel Eval 2017;49:32. https:// doi.org/10.1186/s12711-017-0307-4

29.Wiggans GR, Cole JB, Hubbard SM, Sonstegard SM. Genomic selection in dairy cattle: the USDA experience. Annu Rev Anim Biosci 2017;5:309-27. https://doi.org/10.1146/annurevanimal-021815-111422

30.Elzo MA, Mateescu RG, Johnson DD, et al. Genomic-polygenic and polygenic predictions for nine ultrasound and carcass traits in Angus-Brahman multibreed cattle using three sets of genotypes. Livest Sci 2017;202:58-66. https:// doi.org/10.1016/j.livsci.2017.05.027 